\title{
The Counseling Challenges Facing Muslim Clients across the World
}

\author{
Afaf Osman $^{1 *}$, Ssekamanya Siraje Abdallah ${ }^{1}$ and Abdulfatai Olohunfunmi Ismail ${ }^{1}$ \\ ${ }^{1}$ Department of Educational Psychology and Counseling, Kulliyyah of Education, \\ International Islamic University Malaysia, Kuala Lumpur, Malaysia \\ *Corresponding Author: afaffly@gmail.com
}

\begin{abstract}
This systematic review is conducted with the major aim of highlighting the need for a comprehensive and modern Islamic counselling Model, due to the psychological challenges facing Muslim clients across the world. The main source of data collection in the research is past empirical studies related to the field of counselling as it affects Muslim countries. The study found, from the extant literature reviewed, that there is a high incidence of psychological problems among Muslim populated countries, especially the crises-ridden and turbulent regions such as Syria, Yemen, Palestine and others, as well as among the Muslim minority groups in some countries, such as the US, the UK and other European countries. It was discovered from the literature that the major causes of mental health problems are: lack of the fear of God, wars, poverty, natural disasters, political unrest, discrimination and Islamophobic tendencies. In this regard, the study highlights the need for research and action plans that focus on the well-being of Muslims in the entire global community. It is imperative that Muslims require professional assistance from specially trained counsellors equipped with culturally and Islamically-relevant skills for the mitigation of mental distress and depression. The need for a comprehensive Islamic counselling model that matches and competes with the western-oriented counselling models, is proposed. For precisely this purpose, therefore, the Al-Ghazali counselling model has been recently developed, which is compatible and commensurate with modern scientific therapeutic techniques, and is found to be a highly promising intervention for clients with mental and psychological challenges.
\end{abstract}

Keywords: Islamic counseling, Muslim client, psychological problems

\section{INTRODUCTION}

Counselling as a profession is a noble discipline, which primarily aims to help people with psychological and other related problems. The act of helping people is as old as human history; however, disciplined structural counselling, in reality, commenced after the 2nd World War in the 1950s (Glosoff, 2008). The term counselling has been defined by several authors throughout the ages, but there has been no unanimous agreement on a particular definition. This is because 
the term counselling is a problematic concept to explain. Lack of clarity among the public is due, in part, to the modern-day proliferation of different services that have adopted the label counsellor. They range from credit counsellors to investment counsellors, and from camp counsellors to retirement counsellors. Despite that, their services share the common ingredient of verbal communication, but they have little in common with psychological counselling (Hackney \& Cormier, 2009).

\section{MEANING AND FEATURES OF EFFECTIVE COUNSELING PRACTICES}

Counselling was defined as a situation whereby two people work together, so that the problem may be more clearly defined, and the counselee may be guided to a self-determined solution (Joseph, 1976). It was also seen as a one-on-one relationship that takes place between an individual confronted with challenges that he cannot cope alone and an experienced and trained worker qualified to help others reach solutions to various types of personal problems (Hahn \& Maclean, 1955). More comprehensively, counseling is a professional and formal relationship that empowers different groups, families and individuals to accomplish mental health, wellness, education, and career goals. Given all these, counselling is seen as a helping relationship in which the therapist strives to empower the client for greater functioning.

Meanwhile, effective counselling was reported to possess some characteristics such as emotionally-charged interaction, the confiding relationship between client and counselor; support, warmth, as well as attention from the therapist in a healing setting; a positive therapeutic connection between client and therapist; restoration of hope and expectancy; and procedures consistent with client expectation and efficacy (Kerry, 2005; Fishman,1999; Hubble, et al., 1999).

\section{Integration of Religion with the Counseling Profession}

Often, counsellors interact and deal with clients from different ideological backgrounds who are deeply fixated on their negative belief systems. This has made it imperative for counsellors to be equipped with knowledge about the clients' beliefs as well as their religious background (Vontress, 2003). This is because the client is the focus of the counselling activities (Nickles, 2011). It is, therefore, safe to assume that religion is a belief system that plays a major role in the daily lives of people. If these set of beliefs are altered, it may affect the entire life of the individuals, because they determine how they perceive things, how they think, and even the choices they make throughout their lives. As such, the religious issue is very important in counselling (Podikunju-Hussain, 2006). Subsequently, religion was incorporated into the field of counselling. Studies have confirmed that most people who seek counselling assistance are adherents of religious beliefs. For instance, a study was conducted to assess whether participants would prefer to discuss religious or spiritual issues in a counselling session, and found that more than half of the participants prefer to discuss religious and spiritual issues (Rose, Westfeld \& Ansley, 2001). Avowedly, religion and spirituality are very critical sources of strength for many 
clients (Corey, 2009). Evidently, religion and spirituality are integral to the field of counselling (Kilmer, 2012).

There are several religions across the globe, of which the most prominent are Islam and Christianity. This is because they are organized religions with many followers across the globe. Therefore, it has become a necessity for present-day counsellors to be fully aware of the importance of integrating religious principles into their practice. Christianity, for instance, has been deeply integrated into the formal counselling discipline (Kim, 2004). Islam, on the other hand, despite having been integrated into formal counselling, is not as popular and not fully integrated into the formal counselling profession (Al-Kernawi \& Graham 1994).

\section{Evolution of Islamic Counseling Practices}

The followers of Islam comprise $1 / 5$ of the world's population, and they see Islam as a comprehensive way of life, in contrast to the Western worldview (Brown \& Rabasa, 2005). They believe in it and are pleased with Islamic principles and laws to govern their lives. Therefore, employing the western system of counselling may not be helpful, and might threaten the stability of their faith, because the counselling relationship is mostly anchored in the human mind, which is the source of human ideology. Hence, Islamic counselling was introduced.

The notion of Islamic counselling or Muslim psychotherapy has been in existence since the 9th and 12th centuries, through the work of Al-Balkh and Al-Ghazali and others (Badri, 2013; Soussi, 2016; Arif, 2018). This shows that organized Islamic counselling has been in existence for a long time. However, Islamic counselling, from its inception, was characterized by giving advice (Nasiha), guidance (Irshad), and was fundamentally a helping relationship. This kind of Islamic traditional counselling manifests itself in the form of the ritual healing practices, such as reading the Quran, prayers, following the prophetic tradition. All these have been attested to from several studies as being effective (Al-Krenawi \& Graham, 1994).

Since September 11, the number of Muslim therapists have increased in the U.S. and across the world, because most Muslims have become worried about how they are viewed by others, due to the negative portrayal of them as terrorists in the media. Therefore, Muslims today not only have to deal with the stressors of life but also to defend their values as acceptable and normal (Vontress, 2003). The constant state of fear, contempt, and feeling of embarrassment has led most Muslims to be susceptible to severe stress, depression and other adverse emotions, which increase their need to visit Muslim psychotherapists.

Meanwhile, several psychotherapists have made efforts to incorporate Islamic values and beliefs into their counselling services (Hamdan, 2007). These Muslim counsellors have found religious psychotherapy to be effective for treating Muslim clients presenting with anxiety, depression as well as bereavement. Some Muslim counsellors even specialize in bereavement counselling, using the Islamic prescription of contemplation as a technique, which proves to be effective (Nik \& Nik, 2013). Muslim counsellors from the Middle East provide training on 
multicultural competence, affective empathy, self-efficacy and cognitive training for students (Podikunju-Hussain, 2006). Islamic counselling, evidently, is in operation across the world and has proven to be effective.

It can be discerned from the foregoing that the counselling profession has been continually evolving until the present time. This is largely due to the fact that the world is evolving and developing with technological advancements and innovations in all spheres of life Concomitantly, psychological problems and challenges keep on spreading across the world. Several studies show that psychological problems are markedly higher in recent decades compared to the previous times (Lester, 2013; Olfson, et al., 2015; Twenge et al., 2010).

\section{Counseling Challenges Facing Muslim Clients across the World}

The World Health Organization (WHO, 2014) affirmed that the increase in social inequalities in the present age is associated with the high risk of several common psychological problems. According to the WHO, the general trends in the field of mental health in the past two decades have revealed substantial changes at the global, national, and local levels. A high-quality epidemiological study by the World Federation for Mental Health (2012), has helped to identify the extent and impact of psychological problems as the primary public health challenges and priorities. This shows that the spread of psychological problems from the global perspective is currently on the rise. Even the generational trends in the psychological problems across the world are on the increase (Twenge et al., 2010). In essence, the above-cited empirical studies have indicated an upsurge in psychological problems worldwide.

Apart from the global proliferation of psychological challenges, the sectional escalation in psychological complications is also looming. The most pertinent section to the present study is the Muslim community around the globe. In this sense, psychological problems among Muslims are increasing. For example, Khan and Khan (2017), reported that the trends of murder, suicide and mental health conditions among Muslim majority countries, such as Morocco, Pakistan, Yemen and others, are skyrocketing as a result of violence and conflict. This empirical study, covering 25 years of data, shows a soaring trend of death from suicide. In 2015 alone, the study equally reported that almost 30,000 people committed suicide in countries such as Syria and Iraq (Khan \& Khan, 2017).

In addition, studies from the Muslim majority countries found a sharp increase in mental health issues such as bipolar disorder, anxiety, depression, and schizophrenia (Ahmad \& Mustaffa, 2011). The study identified anxiety disorder and depression as the most common psychological problems. A clinical survey of Arab-Americans reported that $50 \%$ of the participants have symptoms of clinical depression (Mujahid, 2006). A report from the UK House of Parliament revealed that 24\% of Muslims in England cannot work due to one mental illness or the other (Mujahid, 2006). Also, Basit and Hamid (2010), through the Hamdard Center for Health and Human Services, Chicago, presented statistical data of American Muslims that have various psychological problems. 
Table 1

Intake Diagnoses of Muslim Americans at Hamdard Center for Health and Human Services, Chicago $(N=875)$

\begin{tabular}{lc}
\hline \multicolumn{1}{c}{ Diagnosis } & Percent \\
\hline Adjustment Disorder & $43 \%$ \\
Anxiety Disorder & $15 \%$ \\
Mood Disorder & $9 \%$ \\
Obsessive-Compulsive Disorder & $14 \%$ \\
Post Traumatic Stress Disorder (PTSD) & $10 \%$ \\
Schizophrenia and other Psychotic Disorders & $5 \%$ \\
Substance Abuse & $4 \%$
\end{tabular}

Note. Source: Basit and Hamid (2010)

Table 2

Emotional and Behavioral Problems of Young Muslim Americans $(N=712)$

\begin{tabular}{lc}
\hline \multicolumn{1}{c}{ Diagnosis } & Percent \\
\hline ADHD & $16 \%$ \\
Mood Disorder & $15 \%$ \\
Anxiety Disorder & $13 \%$ \\
Schizophrenia & $5 \%$ \\
Adjustment Disorder & $19 \%$ \\
Alcohol and Substance Abuse & $3 \%$ \\
Impulse Control Disorder & $5 \%$ \\
Eating Disorder & $2 \%$ \\
Somatoform Disorder & $1 \%$ \\
Other Issues & $20 \%$ \\
\hline
\end{tabular}

Note. Source: Basit and Hamid (2010)

The figures from the above tables coupled with the reports from the cited empirical studies indicated that mental health challenges are spreading among Muslims. As mentioned earlier, these problems among Muslims in the past were less frequent compared to the present time. This suggests that there could be some situational causes that are responsible for such an increase in psychological problems.

Based on the above explanation, it can be deduced that the mental health challenges sprang up from some source, because for every problem, there must be a reason. In this regard, several studies have highlighted the major causes of mental health challenges among Muslims. The main causes of these challenges are categorized into biological/personal and environmental factors. The biological factors are well taken care of among the Muslims because they have control over these causes as a result of their faith and knowledge that serve as means of adjustment for them.

However, environmental factors are reported to be the major cause of psychological problems among Muslims. Based on WHO reports, war, poverty, abuse, stressful life, natural disasters, and poor nutrition are some examples of environmental causes (WHO, 2014). It is 
even discovered that environmental factors influenced biological/personal factors. This has made it difficult to distinguish between environmental factors and biological/personal factors. Other studies further illustrated that a complex nature by which the environment and the genetic factors interact could lead to schizophrenia and depression, which are the major indicators of mental health problems (Husted et al., 2015). Equally, some environmental factors like life stressors such as sudden death, abuse, natural disaster and war, have been identified as the trigger to psychological problems (Heekin \& Polivka, 2015). Studies have consistently reported that poverty among others is more likely to lead to psychological challenges. For example, U.S. Department of Health and Human Services (2001), reported that people in the lower strata of income are three to two times more likely than those in higher strata of income to have mental health problems.

Within the recent few decades, the turbulent regions such as the Gaza Strip, Iran, Israel, Egypt, Syria, Yemen, and the West Bank have suffered wars, natural disasters, political violence, force and occupation displacement, and have concurrently suffered from mental health problems such as post-traumatic stress disorder (PTSD). Even civilians in these aforementioned regions have been subjected to incessant episodes of violence, inter- and intra-group conflicts, and natural disasters, which have greatly affected their psychological well-being. War not only traumatizes the civilians but also imposes a psychological burden on them, the aftermath of which could lead to psychological/mental problems (Unangst, 2016). Exposure to war has been found to trigger an extremely high level of stress, which could ultimately lead to a wide range of psychological problems (Freh, 2015). An empirical study also found that $87 \%$ of children who are exposed to chemical weapons showed a wide range of psychological symptoms and traumatic reactions (Freh, 2015). It means that the children demonstrated some psychological reactions in response to their being in the area of bombing.

Moreover, natural disasters were discovered to have a high correlation with PTSD (Chetty et al., 2014). PTSD was found to be prevalent among a population examined during the Barn and Marmara earthquakes (Basolgu et al., 2002). It was reported that $43 \%$ of the 1000 sampled suffered PTSD long after six months of the occurrence. Another empirical study by HaghShenas, et al. (2006), investigating adult and children survivors of the 2003 Barn earthquake, found an alarmingly high incidence of PTSD. In essence, a natural disaster is also regarded as one of the major causes of psychological problems.

The recent experiences of Muslim refugees also greatly affect their psychological wellbeing. For instance, the investigation of the Iraqi refugees in California revealed that trauma is the biggest challenge to their psychological and mental well-being (Ziegahn et al., 2013). Another study investigated Afghan refugees and asylum seekers with prolonged exposure to war, who are under international protection. It was found that the participants experienced severe post-traumatic disorders and depressive symptoms (Alemi et al., 2015). One point that can be noted is that most of the above-cited cases of refugees who were victims of wars and poverty were mostly from Muslim majority countries like Iraq, Syria, and Palestine. It means that psychological problems are prevalent among Muslim-populated countries. Hence, the services that have been offered by a few Muslim counsellors and psychotherapists to ameliorate the psychological problems among the Muslim community, must be corroborated. 


\section{Psychological Challenges among Muslim Clients across the World}

The reported cases of several psychological problems among Muslims across the globe are at an alarming state. It is evident from several empirical studies that Muslims' mental health issues call for urgent attention. For example, research by the Mental Health Foundation, Glasgow (2008), found that mental health issues are endemic among Muslim females in Glasgow. Though the problem is common among the low-income and black minority, Yahia (2012) found that psychological disorder is prevalent in the Middle East, which is a 95\% Muslim-populated zone.

Additionally, existing data show high rates of adjustment disorder experienced by Muslim Americans seeking mental health treatment, which may be suggestive of the challenges of acculturation and adjustment, as well as social discrimination and marginalization (American Psychiatric Association, 2018). It was simultaneously reported that younger Muslims, women and Arabs are most likely to experience prejudice based on their religion (Mogahed \& Chouhoud, 2017). Religious discrimination against Muslims is correlated with depression, anxiety, subclinical paranoia, and alcohol use (Heyman et al.,2006; Budhwani et al., 2018). The recent travel and immigration restrictions directed primarily at Muslim countries by the U.S. government have led to traumatizing experiences for many Muslim Americans. In particular, the harsh handling and long detainments by U.S. Customs and Border Protection can be retraumatizing to those already vulnerable (Awaad \& Ali, 2015).

Moreover, within the current socio-political climate, where UK Muslims are increasingly portrayed negatively (Ameli et al., 2007), the mental well-being of this minority group is particularly under threat. Empirical evidence suggests that this predicament may be having a significant effect on the general mental health of the Muslim population. Researchers reported that $50 \%$ of Arab Americans were diagnosed with having clinical signs of depression. (Weatherhead, \& Daiches, 2010; Ali et al., 2005; Amer, 2006). Khan and Khan (2017), also reported that Muslim-populated countries have the highest incidence of psychological problems such as depression, suicide, and other related problems.

The upsurge of psychological problems among Muslims is neither a happenstance, nor the case that primarily being a Muslim renders one vulnerable to mental health problems. Therefore, some causes, which are majorly environmental factors, were reported to trigger psychological problems among Muslims. However, it was identified from the study that one of the major causes of psychological problems is the unwillingness to follow the guidance and teachings of Islam, while the remaining causes can be categorized as incidental (AbdAleati et al., 2016). This is because faith in Allah, which is followed with action, fortifies and prevents the soul against all forms of psychological problems:

"And whoever turns away from My remembrance - indeed, he will have a depressed life, and We will gather him on the Day of Resurrection blind." (Quran 20: 124).

Meanwhile, other identified causes are wars, loss of beloved ones, displacement, natural disasters, and poverty (Yahia, 2012). All these causes are common in Muslim-populated areas 
such as the Middle East. For example, the persistent turbulence and unrest in Palestine, Syria, Libya, Iraq, and Yemen have led many Muslims to be displaced, faced with the loss of their beloved ones, becoming poverty-stricken refugees, and affected by diseases (Alemi, 2015).

Moreover, stigmatization, prejudice and Islamophobic tendencies against Muslims are some of the other causes of psychological problems among Muslims. For instance, Abu-Ras (2003), found that about 70\% reported shame, and 62\% felt embarrassment seeking formal mental health services. Khan and Ecklund (2013), in a study involving 459 Muslims in the United States, revealed similar gender patterns in stigma and help-seeking. Consequently, stigma experts emphasize the need for interventions to be local, culturally specific, and carefully targeted (Ciftci et al., 2013; Carrigan, 2004).

Against the backdrop of recent national and international political events, more attention has been drawn to the mental health needs of Muslims worldwide as a result of the increasing incidents of discrimination and violence against Muslims, immigration problems, refugee resettlement, and asylum crises (Ahmed \& Reddy, 2007; Oppedal, \& Røysamb, 2007; Khan \& Ecklund, 2013; Altalib, 2019). Therefore, there is a strong need for research and applied programs that specifically focus on the well-being of not only the Muslim American communities but also the entire global community, especially amidst the largest spike in antiMuslim hate crimes that corresponded with the 2016 Presidential elections (Awaad \& Ali, 2015). These factors have resulted in an increasing demand to understand the mental health needs of Muslims, with a growing focus on research and publications (Altalib, 2019). This will furnish the Islamic counselling practices with up-to-date methods and interventions which are empirically supported to cater to the unhealthy psychological conditions of the Muslims.

\section{The Necessity for Contemporary and Comprehensive Islamic-Based Counseling Model}

The unhealthy psychological conditions of the Muslims reported above require continuous professional assistance equipped with culturally and Islamically-relevant techniques for the mitigation of distress and depression among the Muslim population (Alemi, 2015). However, most Muslim therapists usually follow the model developed by western-oriented psychotherapists. That is why it was reported that $10 \%$ out of 5.7 million Iraqi children in school are in dire need of psychological assistance (Freh, 2015).

However, it was reported that some western-oriented counsellors and psychotherapists experienced ordeals and challenges in dealing with Islamic faith-based clients as a result of different cultural orientations (Ziegahn et al., 2013). It was similarly reported that, despite the growing size of the Islamic community in the western countries, most western practitioners appear not to have been very well exposed to Islamic values and teachings during their educational careers, which hampered their ability to handle Muslim clients effectively (Heyman et al., 2006; Murdock, 2004). Equally, researchers found that many Muslims are hesitant to seek help from the mental health professionals in Western countries due to the differences in their beliefs and lack of understating on the part of the helping professionals about Islamic values in their treatment modalities. Consequently, Muslims might feel uncomfortable seeking 
psychiatric help to avoid conflicts with their religious beliefs (Sabri \& Vohra, 2013). It means that western-oriented counsellors and psychotherapists are unable to handle Muslim clients effectively; conversely, most Muslims are unwilling to seek therapeutic assistance from them. The number of available Muslim counsellors and psychotherapists on the ground for the task are very minimal, compared to the enormity of the numbers of Muslims with psychological challenges. In this regard, there is a need for more Muslim counsellors competent in the Islamicfocused model.

However, the integrated Islamic counselling in existence does not have a complete Islamic framework or a systematic outline as well as a procedural framework that matches and competes with several western counselling paradigms. For example, Sigmund Freud is the father of the psychoanalytical counselling model; while client-centred therapy and other counselling theories came from Carl Rogers. People all over the world have been using these counselling models for their clients. On the other hand, it was reported that the integrated Islamic counselling practices and theoretical model are deficient (Sabry \& Vohra, 2013). The deficiency here means that it is not complete. It is reported that the current situation concerning Islamic Counseling in the world, especially in Malaysia, is not clear (Zakaria \& Mat-Akhir, 2016).

As such, there is no clear-cut and comprehensive model for Islamic counselling practices. One of the major reasons that could be responsible for this, according to Isgandarova \& O'Connor (2016), is the issue of attaining a balance between unity and diversity in the conceptual definition of some concepts of Islamic counselling, such as Islamic spiritual care. This is because Muslims are very diverse in terms of their ethnicity, culture, nationality, and tradition. For example, some Muslims believe that reciting the Quran for healing is a proper tradition, while some others believe that such an act is an innovation that must be rejected (Isgandarova, 2011).

The problem of diversity in Islam has its origins from two major sources of knowledge, which are the Quran and Hadith. Scholars have their schools of thought with different interpretations (Asni, 2018). Different interpretations lead to diversity in thought and action, which greatly affect how Muslims think, interact and react to issues (Wani, 2015). This is because most Muslims interpret literally the two sources by themselves. This sometimes led to a distortion of the religious text as well as a deviation from the right course of the religion. As a result, there is no uniformity in some religious sources, which are related to counselling practices and psychotherapy. This could lead to diverse Islamic counselling approaches and practices, which can confuse the Muslim clients, especially the newly converted Muslims and the weaker Muslims. 


\section{CONCLUSION}

The need for a comprehensive and modern Islamic counselling model is the main motive behind this study's substantial argument. As a result, this highlights several challenges facing Muslim clients and several causes of their psychological challenges. The evolution of the Islamic counselling practices up to the present time was equally chronicled. Hence, it was found from this narrative that there is an increase of psychological problems among Muslim populated countries, most especially, the crises and turbulent regions such as Syria, Yemen, Palestine and others, as well as among the Muslim minority groups in some countries such as the US, the UK and other European countries. It was discovered from the literature that the major causes of mental health problems are lack of fear of God, wars, poverty, natural disasters, political unrest, discrimination and Islamophobic tendencies. Therefore, the study highlights the need for research and applied programs that fundamentally focus on the well-being of Muslims in the entire global community. It emphasized that Muslims require the professional assistance of a professional counsellor equipped with culturally and Islamically relevant techniques for the mitigation of distress and depression. It finally proposed the need for a comprehensive Islamic counselling model that matches and competes with the western-oriented counselling models. In favour of this, the Al-Ghazali counselling model has been recently developed, which has comprehensively and scientifically highlighted modern appropriate therapeutic techniques with promising effective interventions to assuage client psychological challenges. 


\section{REFERENCES}

AbdAleati, N. S., Zaharim, N. M., \& Mydin, Y. O. (2016). Religiousness and mental health: Systematic review study. Journal of Religion and Health, 55(6), 1929-1937.

Abu-Ras, W. (2003). Barriers to services for Arab immigrant battered women in a Detroit suburb. Social Work Research and Evaluation, 3(4), 49-66.

Ahmad, R., \& Mustaffa, M. S. (2011). Effect of group guidance using al- Ghazali approach in handling sexual behaviour deviation student. International Conference on Social Science and Humanity, 5, 436-440.

Ahmed, S, \& Reddy, L. A. (2007). Understanding the mental health needs of American Muslims: recommendations and considerations for practice. Journal of Multicultural Counseling and Development, 35, 207-218.

Alemi, Q., James, S., Cruz, R., Zepeda, V., \& Racadio, M. (2015). Psychological distress in Afghan refugees: A mixed-method systematic review. Journal of immigrant and minority health, 16(6), 1247-1261.

Ali, O. M., Milstein, G., \& Marzuk, P. M. (2005). The Imam's role in meeting the counselling needs of Muslim communities in the United States. Psychiatric Services, 56(2), 202-205.

Al-Krenawi, A., \& Graham, J. (1994). Islamic counselling and psychotherapy. Development Quarterly, 43, 1-9.

Altalib, H. H., Elzamzamy, K., Fattah, M., Ali, S. S., \& Awaad, R. (2019). Mapping global Muslim mental health research: analysis of trends in the English literature from 2000 to 2015. Global Mental Health, 6. https://doi.org/10.1017/gmh.2019.3

Ameli, S., Mohammed Marandi, S., Ahmed, S., Kara, S., \& Merali, A. (2007). The British media and Muslim representation: The ideology of demonisation. Retrieved from http://www.ihrc.org. uk/file/1903718317.pdf

Amer, M. M., (2006). When multicultural worlds collide: Breaking down barriers to service use. Paper presented at the annual meeting of American Psychological Association. New Orleans.

American Psychiatric Association. (2018). Mental Health Disparities: Muslim Americans. Psychiatry.Org, 1-6.

Arif, S. (2018). Ghazali's personality theory: a study on the importance of humility in early childhood (Master's thesis, Ibn Haldun University, Alliance of Civilization Institute).

Asni F., (2018). The model of Istinbat by the shariah advisory council of central bank of Malaysia, council of central bank of Malaysia. International Journal of Academic Research in Business and Social Sciences, 8 (1), 12 -2

Awaad, R., \& Ali, S. (2015). Obsessional disorders in al- Balkhi's 9th century treatise: Sustenance of the body and soul. Journal of Affective Disorders, 180, 185- 189. http://dx.doi.org/10.1016/j.jad.2015.03.003 
Badri, M. (2013). Translation and annotation of Abu Zayd al-Balkhi's Sustenance of the Soul. Richmond, VA: International Institute of Islamic Thought.

Basit, A. \& Hamid, M. (2010). Mental Health Issues of Muslim Americans. The Journal of IMA / Islamic Medical Association of North America. 42.

Basoglu, M., Salcioglu, E., \& Livanou, M. (2002). Traumatic stress responses in earthquake survivors in Turkey. Journal of Traumatic Stress, 15, 269-276.

Brown, L. C., \& Rabasa, A. M. (2005). The Muslim World after 9/11. In Foreign Affairs (Vol. 84). https://doi.org/10.2307/20034326

Budhwani H., Borgstede S., Palomares A. L., Johnson R.B., \& Hearld K R. (2018). Behaviors and risks for cardiovascular disease among muslim women in the United States. Health Equity, 2(1):264-271.

Chetty, S., Friedman, A. R., Taravosh-Lahn, K., Kirby, E. D., Mirescu, C., Guo, F., ... \& Kaufer, D. (2014). Stress and glucocorticoids promote oligodendrogenesis in the adult hippocampus. Molecular psychiatry, 19(12), 1275-1283.

Ciftci, A., Jones, N., \& Corrigan, P. W. (2012). Mental health stigma in the Muslim community. Journal of Muslim Mental Health, 7(1), 17-32. https://doi.org/10.3998/jmmh. 10381607.0007.102

Corey, G. (2009). Theory and Practice of Counseling and Psychotherapy (8th ed.). Thompson Higher Education.

Corrigan, P. W. (2004). How stigma interferes with mental health care. American Psychologist, 59, 614-625. http://dx.doi.org/10.1037/0003-066X.59.7.614

Fishman, D. (1999). The case for pragmatic psychology. New York, NY: University Press.

Freh, F. M. (2015) Psychological effects of war and violence on children. Journal of Psychological Abnormalities, 1-2. https://doi.org/10.4172/jpab. S1-e001

Glosoff, H. L. (2008). The Counseling Profession: Historical Perspectives and Current Issues and Trends.

Hackney, H., \& Cormier, S. (2009). The professional counselor: A process guide to helping (6th ed). Upper Saddle River: Pearson.

Hagh Shenas, H., Goodarzi, M. A., Farajpoor, M., \& Zamyad, A. (2006). Post-traumatic stress disorder among survivors of Bam earthquake 40 days after the event. EMHJ-Eastern Mediterranean Health Journal, 12 (Supp. 2), S118-S125, 2006.

Hahn, M. E., \& Maclean, M. S. (1955). Counseling psychology (2nd ed.). McGraw-Hill.

Hamdan, A. (2007). A Case Study of a Muslim Client: Incorporating Religious Beliefs and Practices. Journal of Multicultural Counseling and Development; ProQuest Education Journals, 35(2).

Heekin, K. and Polivka, L. (2015) 'Environmental and Economic Factors Associated with Mental Illness', The Claude Pepper Center Florida State University, (November). 
Heyman J., Buchanan R., Musgrave B., \& Menz V. (2006). Social workers' attention to clients' spirituality: Use of spiritual interventions in practice. Arete 2006;30:78-89.

Hubble, M., Duncan, B., \& Miller, S. (1999). The heart and soul of psychotherapy: What works in psychotherapy. Washington, DC: American Psychologists Association.

Husted, J. A., Ahmed, R., Chow, E. W. C., Brzustowicz, L. M., \& Bassett, A. S. (2012). Early environmental exposures influence schizophrenia expression even in the presence of strong genetic predisposition. Schizophrenia Research, 137(1-3): 166-168.

Isgandarova N. \& O’Connor, T. (2016). A Redefinition and Model of Canadian Islamic Spiritual Care. Ontario Canada

Isgandarova, N. (2011). Effective Islamic spiritual care: foundations and practices of Imams and other Muslim spiritual caregivers. Doctor of Ministry Thesis, Waterloo, ON: Wilfrid Laurier University

Joseph F. P. (1976). Family counseling, theory and practice, Van Nostrand

Kerry, B. B. (2005). The Elements of Effective Teaching. Journal of Staff Development, 32(6), $10-16$.

Khan, M, \& Ecklund, K (2013). Attitudes toward Muslim Americans post-9/11. Journal of Muslim Mental Health 7, 1-16.

Khan, S., \& Khan, R. A. (2017). Chronic Stress Leads to Anxiety and Depression. SciMedcentral, 5, 14-17.

Kilmer, C. (2012). Integrating spirituality and religion into counseling.

Kim, Y. T. (2004). A Christian counseling model: Christian psychology perspective. Torch Trinity Journal, 7, 237-254.

Lester, D. (2013). Hopelessness in undergraduate students around the world: A review. Journal of Affective Disorders, 150, 1204-1208.

Mental Health Foundation Glasgow. (2008). Mental Health Issues amongst Muslim Women Residing in South East Glasgow Community Health and Care Partnership Boundary : A Study of Their Beliefs, Knowledge and Service Access Issues A Research Report by REACH Community Health November 2008 Funded by. Reach Community Health Project, (November), 1-67.

Mogahed D., \& Chouhoud Y. ( 2017): Muslims at the Crossroads. Institute for Social Policy and Understanding American Muslim Poll Accessed 12/5/18 https://www.ispu.org/wpcontent/uploads/2017/03/American-Muslim-Poll-2017-Report.pdf.

Mujahid, A. M. (2006) 'State of Muslim mental health', https://www.soundvision. com/article/state-of-muslim-mental-health, pp. 0-2.

Murdock, V. (2004) Religion and spirituality in gerontological social work practice: Results of a national survey; 2004.10.1007/s10943-014-9896-1. 
Nickles, T. (2011). The role of religion and spirituality in counseling. Journal of the College of Physicians and Surgeons--Pakistan : JCPSP, 14, 453-454.

Nik R. \& Nik Y. (2013). Cognitive Therapy Approach from Islamic Psycho- spiritual Conception. Procedia - Social and Behavioral Sciences, 97, 182-187. http://doi.org/10.1016/j.sbspro.2013.10.220

Olfson, M., Druss, B. G., \& Marcus, S. C. (2015). Trends in mental health care amongst children and adolescents. New England Journal of Medicine, 372, 2029- 2038.

Oppedal, B., \& Røysamb, E. (2007). Young Muslim immigrants in Norway: an epidemiological study of their psychosocial adaptation and internalizing problems. Applied Development Science 11, 112-125.

Podikunju-Hussain, S. (2006). Working With Muslims: Perspectives and Suggestions for Counseling. VISTAS Online, ACA Knowledge Center.

Purity, N., Theresa, A., \& Chidimma, I. I. (2019). Competitive Intelligence and Organizationa Performance in Selected Deposit Money Banks in South-East , Nigeria. International Journal of Trend in Scientific Research and Development (IJTSRD), 1(6).

Rose, E. M., Westfeld, J. S., \& Ansley, T. N. (2001). Spiritual issues in counseling: Clients' beliefs and preferences. Journal of Counseling Psychology,48, 61-71.

Sabry, W. M., \& Vohra, A. (2013). Role of Islam in the management of Psychiatric disorders. Indian Journal of Psychiatry, 55(SPEC. SUPPL.). https://doi.org/10.4103/00195545.105534

Soussi, K. (2016). Al Ghazali Cultivates Education: A Comparison with Modern Theories. International Journal of Education and Research, 4(11), 425-436.

Twenge, J. M., Gentile, B., DeWall, C. N., Ma, D. S., Lacefield, K., \& Schurtz, D. R. (2010). Birth cohort increases in psychopathology among young Americans, 1938-2007: A crosstemporal meta-analysis of the MMPI. Clinical Psychology Review, 30, 145-154.

U.S. Department of Health and Human Services. (2001). Mental Health: Culture, Race, and Ethnicity-A Supplement to Mental Health: A Report of the Surgeon General. Rockville, MD: U.S. Department of Health and Human Services, Substance Abuse and Mental Health Services Administration, Center for Mental Health Services.

Unangst, F. M. (2016) 'The History and Psychological Effects of Middle Eastern Conflict', https://history 105.libraries.wsu.edu/fall2016-unangst, pp. 1-4.

Vontress, C. E. (2003). Culture and Counseling Culture and Counseling. Online Readings in Psychology and Culture, International Association for Cross-Cultural Psychology, 10, 19.

Wani, H., Abdullah, R., \& Chang, L. W. (2015). An Islamic perspective in managing religious diversity. Religions, 6(2), 642-656. https://doi.org/10.3390/rel6020642

Weatherhead, S., \& Daiches, A. (2010). Muslim views on mental health and psychotherapy. Psychology and Psychotherapy: Theory, Research and Practice, 83(1), 75-89. https://doi.org/10.1348/147608309X467807 
WHO (2014). Mental health: a state of well-being. World Health Organization (WHO) (2012). Mental Health Gap Action Programme (mhGAP): Scaling up care for mental, neurological, and substance use disorders. Retrieved 29 June 2012.

World Federation for Mental Health. (2012). DEPRESSION: A Global Crisis

Yahia, M. (2012). Dealing with mental illness in the Middle East. Nature Middle East.

Zakaria N. \& Mat-Akhir N. (2016) Theories and Modules Applied in Islamic Counseling Practices in Malaysia. Journal of Religion.

Ziegahn, L., Ibrahim, S., Al-Ansari, B., Mahmood, M., Tawffeq, R., Mughir, M., \& Xiong, G. (2013). The mental and physical health of recent Iraqi refugees in Sacramento, California. 